\title{
UM OLHAR PARA O TRABALHO COM O GÊNERO CONVITE EM TURMAS DE ALFABETIZAÇÃO
}

\section{A LOOK AT THE WORK WITH THE GENRE “INVITATION” IN CLASSES OF LITERACY}

\section{Terezinha da Conceição Costa-Hübes}

Professora do Programa de Pós-graduação Stricto Sensu em Letras - nível de Mestrado e Doutorado - da UNIOESTE; Coordenadora do Projeto de Pesquisa Formação Continuada para Professores da Educação Básica nos anos iniciais: ações voltadas para a Alfabetização em Municípios com Baixo IDEB da Região Oeste do Paraná, vinculado ao Programa

Observatório da Educação - CAPES/INEP e à Linha de Pesquisa Linguagem: Práticas Linguísticas, Culturais e de Ensino. tehubes@gmail.com

\section{Mônica de Araújo Saraiva}

Mestre pelo Programa de Pós-graduação Stricto Sensu em Letras — nível de Mestrado e Doutorado - da UNIOESTE, Campus de Cascavel, inserida na linha de Pesquisa Linguagem: práticas linguísticas, culturais e de ensino, sob orientação da $\operatorname{Prof}^{\mathrm{a}} \operatorname{Dr}^{\mathrm{a}}$ Terezinha da Conceição Costa-Hübes. Pesquisadora, bolsista Capes, integrante do Projeto de Pesquisa

Formação Continuada para Professores da Educação Básica nos anos iniciais: ações voltadas para a Alfabetização em Municípios com Baixo IDEB da Região Oeste do Paraná, vinculado ao Programa Observatório da Educação.

monyka-s@uol.com.br

RESUMO: O presente texto é resultado de estudos, reflexões e pesquisas articuladas ao Projeto Formação Continuada para Professores da Educação Básica nos anos iniciais: ações voltadas para a Alfabetização em Municípios com Baixo IDEB da Região Oeste do Paraná, vinculado ao Programa Observatório da Educação - CAPES/INEP. Nesse contexto, nossa pesquisa, em específico, focaliza-se em ações de mediação na apropriação da linguagem escrita por meio do trabalho com gêneros discursivos. Assim, como parte desse processo investigativo, objetivamos, neste artigo, analisar atividades de produção escrita de textos em uma turma do $2^{\circ}$ ano (anos iniciais), a partir de um trabalho mediado com o gênero convite. Guiadas pela indagação: "como a mediação do professor, durante o trabalho com gêneros discursivos na perspectiva da alfabetização, pode contribuir com a aquisição da linguagem escrita de alunos do $2^{\circ}$ ano do ensino fundamental?", pretendemos refletir sobre um encaminhamento didático-metodológico em um processo investigativo qualitativo, do tipo etnográfico, respaldado na metodologia da pesquisa-ação, com o gênero convite, na perspectiva de ressaltar a importância da mediação do professor durante esse processo de ensino. Trata-se, portanto, de uma pesquisa cunhada na Linguística Aplicada, recorrendo a aportes teóricos da Psicologia Histórico-Cultural (VYGOTSKI, 1995, 2001, 2007) e da concepção Dialógica de Discurso (BAKHTIN/VOLOCHINOV, 2004; BAKHTIN, 2003), logo, dentro da abordagem sócio-histórica da linguagem. Buscamos, também, apoio teórico nos estudos de Geraldi (2003, 2006), Cagliari (2009, 1998), Martins (2007) e em outros autores que abordam sobre a inserção da criança na interação social por meio da escrita. Os 
resultados são reveladores da importância da intervenção do professor frente às atividades que promovam a apropriação da linguagem escrita.

PALAVRAS-CHAVE: Alfabetização. Apropriação da linguagem escrita. Gêneros discursivos

ABSTRACT: This paper is the result of studies, reflections and articulated research to the project Continuing Education for Teachers of Basic Education in the lower elementary school: actions to literacy in cities with low IDEB of Western Paraná, linked to the Centre for Education Program - CAPES/INEP. In this context, our research, in particular, focuses on actions to mediate the appropriation of writing by working with speech genres language. Thus, as part of this investigative process, we aim in this paper to analyze the written text activities in a class of 2nd year (lower elementary school), considering a work using the gender invitation. Guided by the question: "how mediation of the teacher, while working with speech genres from the perspective of literacy, may contribute to the acquisition of written language of students in the 2nd year of elementary school? - Intend to reflect on a didactic - methodological strategies on a qualitative research process, of the ethnographic type, endorsed by the methodology of action research, with gender invitation, from the perspective of emphasizing the importance of the teacher's role as mediator during this teaching process. It is, therefore, a research in Applied Linguistics, using the theoretical framework of Cultural-Historical Psychology (VYGOTSKY, 1995, 2001, 2007) and the concept of Dialogic Discourse (BAKHTIN/VOLOCHINOV, 2004; BAKHTIN, 2003), being within of the socio-historical approach to language. We also seek support in theoretical studies such as Geraldi (2003, 2006), Cagliari (2009, 1998), Martins (2007), and other authors who address on the inclusion of children in social interaction through writing. The results reveal the teacher importance of "intervention" in activities that facilitate the appropriation of the written language.

KEYWORDS: Literacy. Appropriation of written language. Speech genres

\section{INTRODUÇÃO}

Compreender a linguagem como social, histórica e ideológica significa abalizar as condições humanas de interação, reconhecendo os sujeitos nessa imersão social, (re)construindo-se na relação com o(s) outro(s). Nas condições de interação, os discursos são organizados em função do contexto, atendendo ao propósito de fazer-se compreendido pelo(s) outro(s) com o(s) qual(is) enuncia. Para abarcar as necessidades estabelecidas, a linguagem se amplia, se renova, se constitui, se ramifica, tendo como preceito, apenas, seu compromisso com a interação. Nessa alquimia da "inter-ação", fundam-se os pilares do discurso, moldado em função do que, como, quando, onde e para quem dizer. Como diz Bakhtin: "o emprego da língua efetua-se em forma de enunciados (orais e escritos) concretos e únicos" (BAKHTIN, 2003, p. 261), já que se configuram para uma situação específica, em um dado momento histórico e para aquela situação de interação.

Partindo dessa compreensão, o objetivo que orientou o processo investigativo foi o de analisar a prática pedagógica, tendo em vista a identificação de ações de mediação na apropriação da linguagem escrita, durante a efetivação de um plano de trabalho com os gêneros contos de fadas e convites ${ }^{1}$. Sustentada pela metodologia da pesquisa-ação, nossa pesquisa se amparou

\footnotetext{
${ }^{1}$ Nesse texto, devido ao recorte necessário, focaremos apenas no gênero convite.
} 
nos fundamentos que norteiam a concepção sócio-histórica da linguagem, conforme Bakhtin/Volochinóv (2004) e Bakhtin (2003), assim como na psicologia histórico-cultural de Vygotsky (1995, 2001, 2007).

Se ampararmos o ensino nesses pressupostos, não podemos ignorar a dinamicidade da língua e o fato de ela constituir-se para/em situações de uso da linguagem. Sendo assim, cabe-nos planejar seu ensino a partir dos usos reais, (re)significados nos diferentes gêneros discursivos. O trabalho com os gêneros comporta, desde os anos iniciais, a análise e a compreensão do funcionamento e dos mecanismos que organizam a linguagem oral e escrita. Logo, tomá-los como instrumentos culturais que favoreçam essa apropriação, significa embasar o ensino da língua em preceitos socialmente construídos.

Nesse sentido, o processo de apropriação da linguagem escrita perpassa pela compreensão dos signos historicamente e socialmente produzidos pela humanidade, pois é por meio de signos que atuamos socialmente em resposta às necessidades e propósitos de interação como locutores e interlocutores. Logo, reconhecê-los e compreendê-los é uma condição para a inserção social. Como diz Vygotsky, "o homem é uma criatura social, e as condições socioculturais o modificam profundamente [...]" (VYGOTSKY, 1996, p. 220). Assim, a escola deve ser o espaço por excelência de promoção dessas modificações, favorecendo, aos sujeitos, o domínio de instrumentos que possibilitem a sua inserção e participação na sociedade letrada. Apoderar-se da linguagem escrita e ter acesso pleno à leitura são condições estabelecidas por uma sociedade grafocêntrica que, a cada dia mais, exige de seus cidadãos essas capacidades.

É sobre essa língua socialmente estabelecida e as relações que a circundam que vamos discorrer neste texto, tomando como referência encaminhamentos didáticos com o gênero convite, a fim de analisar nossa prática pedagógica, tendo em vista a identificação de ações de mediação na apropriação da linguagem escrita. Para isso, organizamos o texto da seguinte forma: primeiramente traçamos algumas reflexões sobre o ensino de língua portuguesa nos anos iniciais, abordando brevemente o processo de alfabetização e o trabalho com os gêneros discursivos; a seguir, socializamos práticas de leitura e produção escrita de textos do gênero convite em turmas do segundo ano do ensino fundamental, a fim de apresentarmos algumas possibilidades de trabalho com o gênero em turmas de alfabetização; por fim, encerraremos com algumas considerações sobre o trabalho apresentado.

\section{O TRABALHO COM A LÍNGUA PORTUGUESA NOS ANOS INICIAIS}

Pensar o trabalho com a Língua Portuguesa (LP, doravante) requer, antes de tudo, refletir sobre seu objeto de ensino e sobre os usos que o aluno estabelece socialmente, com conteúdos inerentes à língua materna. Nesse sentido, os encaminhamentos didáticos, relacionados ao ensino da língua, dentro da perspectiva da alfabetização, devem provocar em nós, professores, ações e intervenções pela atividade mediadora, de forma que a língua seja portadora de significação social e seja reconhecida pelo aluno como instrumento de interlocução mediante a uma intencionalidade. Na efetivação desse trabalho, é preciso estar consciente de que a educação é um bem a serviço da emancipação social do aluno, que se concretiza pela apropriação do conhecimento produzido ao longo da história da humanidade. Nesse sentido, Cagliari (2009) contribui ao afirmar que

[...] o objetivo mais geral do ensino de língua portuguesa para todos os anos da escola é mostrar como funciona a linguagem humana e, de modo 
particular o português; quais os usos que tem, e como os alunos devem fazer para estenderem ao máximo, ou abrangendo metas específicas, esses usos nas suas modalidades escrita e oral, em diferentes situações da vida. Em outras palavras, o professor de língua portuguesa deve ensinar aos alunos o que é uma língua, quais as propriedades e usos que ela realmente tem, qual é o comportamento da sociedade e dos indivíduos com relação aos usos lingüísticos, nas mais variadas situações de sua vida (CAGLIARI, 2009, p. 24).

Todavia, não podemos desconsiderar que o aluno, ao ingressar na escola, já traz consigo domínios sobre sua língua materna. Esses conhecimentos, de modo geral relacionados à oralidade, podem ser considerados e tomados como ponto de partida, objetivando elevar esse conhecimento para o domínio dos aspectos convencionais relacionados à leitura e à escrita. Segundo Cagliari, "para que os sistemas de escrita continuem a ser usados, é preciso ensinar às novas gerações como fazê-lo" (CAGLIARI, 1998, p.12), afinal esse é um legado deixado à escola: estender o conhecimento da leitura e da escrita a cada nova geração, socializando os saberes que são próprios da cultura da escrita.

Tendo em vista a natureza social da linguagem, é importante que, desde a compreensão e o traçado da primeira letra, a criança seja conscientizada da função integralizadora da linguagem, presente tanto no ato da leitura quanto no da escrita. Seus usos fundamentam-se na presença de um interlocutor, já que escrevemos para que alguém, fazendo uso do conhecimento de uma convencionalidade histórica e social, comum entre os sujeitos envolvidos, interaja e dialogue por meio das significações estabelecidas pela escrita.

Ao pensarmos no processo de alfabetização, é importante recorrer às questões propostas por Geraldi: "para que ensinamos o que ensinamos [...] para que as crianças aprendem o que aprendem?" (GERALDI, 2006, p. 40). A ausência dessa reflexão pode ofuscar e comprometer o processo de ensino e aprendizagem da linguagem escrita, pois corre-se o risco de direcionar as atividades e reflexões apenas aos fenômenos estruturais da língua, esquecendo-se de sua função na sociedade. Trabalhar com a linguagem escrita envolve os aspectos fundamentais que justifica, desde os primórdios, a interação entre sujeitos.

Para compreender os recursos usados em uma produção escrita e o sentido que expressam, é preciso refletir sobre a língua, compreendendo sua dimensão dialógica. Nesse sentido, vale retomar as palavras de Bakhtin/Volochinov (2004), para quem a verdadeira substância da língua se encontra na interação verbal entre sujeitos sociais, que promovem a linguagem por meio de seu uso em diferentes situações sócio-comunicativas. Assim,

A verdadeira substância da língua não é constituída por um sistema abstrato de formas lingüísticas nem pela enunciação monológica isolada, nem pelo ato psicofisiológico de sua produção, mas pelo fenômeno social da interação verbal, realizada através da enunciação ou das enunciações. A interação verbal constitui assim a realidade fundamental da língua (BAKHTIN/VOLOCHINOV, 2004, p. 123, grifos no original).

Portanto, é na relação interindividual que se torna possível a concretização da língua. Tomando essa orientação como princípio, é preciso reconhecer a leitura e a escrita como ações sociais que permeiam todo e qualquer trabalho com a linguagem. E, ao propiciar práticas efetivas com a leitura e a escrita na escola, estas deveriam organizar-se de forma que 
promovessem a autonomia do aluno, ampliando seus horizontes e capacitando-o para atividades conscientes de interação.

Nesse sentido, Martins reforça que "o produto do trabalho educativo revela-se na promoção da humanização dos homens, na consolidação de condições facilitadoras para que os indivíduos se apropriem do saber historicamente sistematizado pelo gênero humano" (MARTINS, 2007, p. 5). Logo, as ações com a linguagem, fundamentadas em seus usos sociais, favorecem a apropriação da leitura e da escrita quando estas fizerem parte de um trabalho preocupado com a promoção de sujeitos sociais. Para isso, defendemos que os gêneros discursivos devam ser tomados como instrumentos para o ensino da língua, pois muitos deles, além de recuperarem o surgimento da escrita, registram a história da humanidade e revelam seus diferentes usos na atualidade, bem como colaboram para a promoção da cultura da humanidade.

Assim, ao abordar questões relacionadas ao processo de alfabetização, não podemos desconsiderar a sua especificidade, e isso exige que nossas ações docentes ampliem as possibilidades de participação do aluno em atividades que envolvem os usos sociais da linguagem, o que demanda a apropriação do sistema da escrita. Segundo Cagliari,

[...] a criança que se inicia na alfabetização já é um falante capaz de entender e falar a língua portuguesa com desembaraço e precisão nas circunstâncias de sua vida em que precisa usar a linguagem. Mas não sabe escrever nem ler. Esses são usos novos da linguagem para ela, e é sobretudo isso o que ela espera da escola (CAGLIARI, 2009, p. 25).

O conhecimento com o qual a criança adentra na escola jamais poderá ser ignorado no processo de ensino e aprendizagem; ao contrário, deve ser concebido como ponto de partida para o trabalho com outras formas de interação por meio da linguagem escrita. Stemmer (2007), ao abordar a importância do aprendizado da leitura e da escrita, destaca que esse compromisso deve ser prioritário no sistema escolar, visto que o domínio da escrita tornou-se uma necessidade histórica, promovedora das relações sociais entre os sujeitos.

Para que a apropriação da escrita se efetive como um bem social, o professor pode atuar intervir e propor constantemente atividades de reflexão e de análise da linguagem, de forma que contribua com inserção de seu aluno no mundo da escrita. Esse processo de reflexão colaborativa se faz necessário visto que o aluno, principalmente nos primeiros ciclos do ensino fundamental, está construindo internamente o domínio dos aspectos formais da língua escrita, desenvolvendo-os por meio de ações mediadas pelos signos sociais presentes.

Por isso, é muito importante que a criança entenda a significação da escrita para a sua vida e para a humanidade e se aproprie da sua função social. Segundo Cagliari (1998), essa compreensão pode assentar-se em uma análise do surgimento da escrita, justificado pelo ato da leitura. Quem escreve almeja ser compreendido por meio da atividade de leitura, pois a escrita não existe no vazio, e sim, em função de uma necessidade socialmente estabelecida, seja ela de registrar alguma memória ou convidar, avisar, nomear, entre outras finalidades.

Considerando tais pressupostos sociais de uso da escrita, destacamos a importância do trabalho com os gêneros discursivos desde os anos iniciais, pois se a escola é um espaço privilegiado de mediação do conhecimento, deve favorecer a sua transformação e apropriação por meio dos diferentes usos da linguagem. Nesse sentido, cabe a ela proporcionar aos alunos o contato com a diversidade dos gêneros discursivos existentes a fim de que os alunos possam 
não só (re)conhecê-los, mas também empregá-los em diferentes situações de interação, manifestando, assim, o conhecimento adquirido. Para isso, como professores, devemos assumir o compromisso de proporcionar meios eficientes para que o aluno possa não só conhecer os discursos existentes, mas atuar sobre eles como um instrumento de interação, seja no papel de locutor ou interlocutor.

Se, como afirmam Martins e Arce (2007), "a criança precisa dominar os mecanismos das ações e operações realizadas no cotidiano [...]”, (MARTINS; ARCE, 2007, p. 23), os gêneros discursivos são os meios pelos quais organizamos socialmente nossos modos de dizer. Dessa forma, o trabalho intencional com diferentes gêneros podem favorecer não somente a apropriação da leitura e da escrita, mas também dos mecanismos linguístico-discursivos que organizam e sustentam os discursos em função de um por que e para que(m) dizer, justificando os conteúdos referentes à leitura e à escrita.

As práticas de leituras e de escritas devem representar ações com a linguagem. Dessa forma, os gêneros discursivos, que são constituídos por linguagem viva, representam a dinamicidade da língua que pode e deve ser ensinada na escola. Abordar o ensino da linguagem escrita a partir de gêneros é uma forma de garantir-lhe maior significação, pois faz-se necessário que o aluno compreenda "o que" e "como" escrever, bem como a funcionalidade da escrita nos diferentes gêneros discursivos.

Com relação ao trabalho com a escrita em turmas no processo inicial de alfabetização, Cagliari (1998) destaca que

Ensinar as crianças a tornar conscientes os procedimentos de decifração da escrita é uma estratégia que as agradam mais do que ficarem repetindo coisas aparentemente sem sentido, ou ser largadas a própria sorte, esperando que saiam de dentro de si os conhecimentos que a escola exige para ler e escrever (CAGLIARI, 1998, p. 9).Ao contrário disso, ensinar a ler e a escrever significa promover a criança à condição de sujeito participante da história da humanidade, construindo discursos também por meio da linguagem escrita.

Apesar das orientações pedagógicas, tanto na formação inicial quanto na continuada, direcionarem para a realização de um trabalho voltado à apropriação da linguagem escrita atrelada aos seus usos sociais, percebemos uma grande dificuldade, por parte dos professores alfabetizadores, no trabalho didático a partir dos gêneros discursivos que circulam socialmente.

Tal fato parece apontar para a existência de um distanciamento entre a teoria propagada pelos documentos pedagógicos e pelas instituições formadoras, e a prática efetivada na sala de aula. Essa percepção, inicialmente empírica, direcionou-nos para a necessidade de olharmos para as ações de mediação no trabalho com os gêneros discursivos no processo de apropriação da linguagem escrita pelos alunos. Na perspectiva de apresentar algumas contribuições para o trabalho com os gêneros durante o processo de apropriação da linguagem escrita, abordamos, a seguir, algumas possibilidades de trabalho com o gênero convite, tomando como parâmetro uma turma do $2^{\circ}$ ano do Ensino Fundamental.

\section{O GÊNERO CONVITE NA SALA DE AULA: SOCIALIZANDO UM PROCEDIMENTO DE ENSINO}

A turma de $2^{\circ}$ ano, locus da pesquisa, era formada por 23 alunos, pertencentes a uma escola da rede municipal de ensino de Cascavel - PR, na qual atuamos como professora regente em 2012. E pela experiência acumulada nesse nível de ensino, consideramos essa fase como o 
momento essencial para destacar a importância da leitura e da escrita na formação de sujeitos críticos e participativos da vida na sociedade. Logo, as práticas de leitura e de escrita no trabalho com o processo de alfabetização precisam promover atividades de análise e reflexão sobre a língua, a partir da linguagem escrita em situações reais de uso, garantidas em diferentes gêneros discursivos.

Partindo desse pressuposto, selecionamos o gênero convite para efetivação de um plano de trabalho de leitura, de produção textual e de análise linguística, recorrendo às práticas de reescrita para provocar, nos alunos, a análise crítica de seu texto. A escolha do gênero em questão se justifica pelo fato de as crianças, desde cedo, envolverem-se com essa forma de linguagem, manifestada principalmente nos convites de aniversários.

Partindo desse princípio, levamos para a sala de aula diversas amostras de textos do gênero, a partir das quais promovemos atividades de reflexão coletiva sobre seu contexto de produção e de circulação. Consideramos diferentes situações de uso, uma vez que o convite se configura diferentemente para cada situação, quando se trata da escrita: convite de reunião da escola, de reunião de empresas, de aniversário, de casamento, de festa junina etc., e de diferentes maneiras ainda quando se materializam na oralidade.

Pautando-nos em tais reflexões, tomamos como exemplo o texto seguinte, uma amostra do gênero convite de reunião da escola, sobre o qual desenvolvemos a análise descrita a seguir:

Figura 1: Convite para reunião na escola

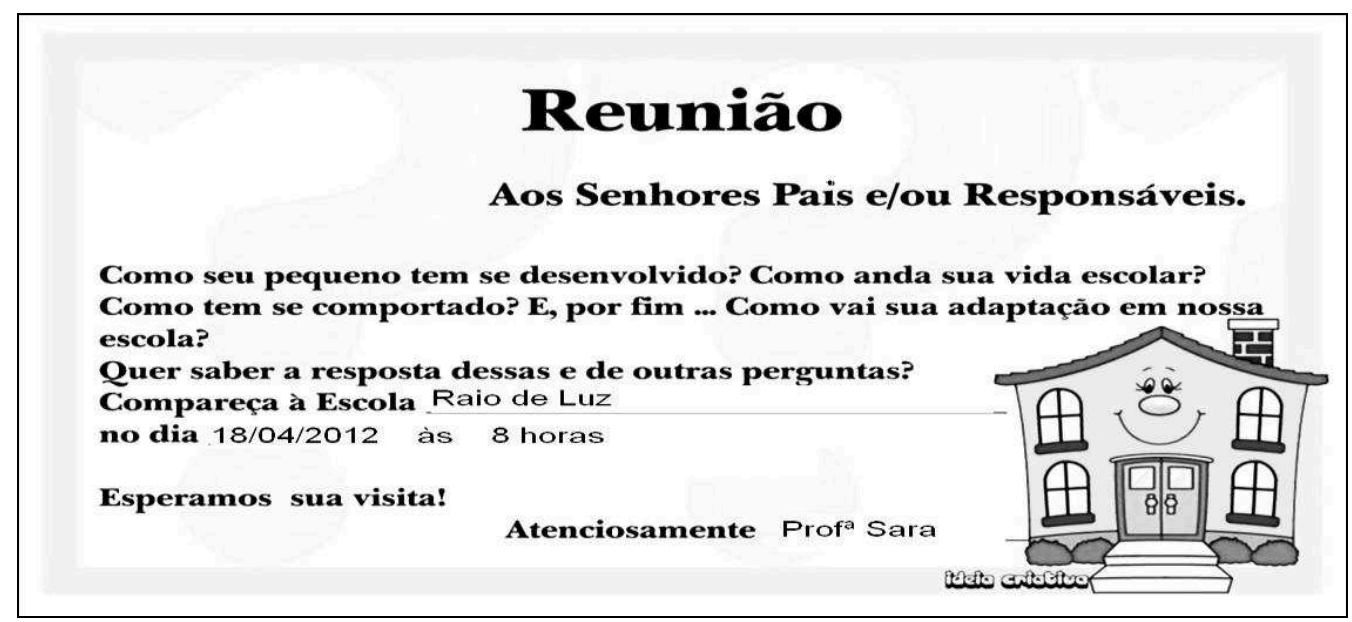

Fonte: http://gibarbosa1.blogspot.com.br/2010/08/modelo-de-convite-p-reuniao-de-pais-e.html

Consideramos, para este trabalho que, em relação à interação da criança com a linguagem escrita, "quanto mais ricas e diversificadas forem [...], maior será seu interesse em compreender e dominar o sistema da escrita" (STEMMER, 2007, p. 132). Nesse sentido, é importante destacarmos que os alunos dessa turma de $2^{\circ}$ ano constantemente realizavam, sob nossa mediação, atividades de leitura, compreensão e interpretação de diferentes textos pertencentes a diversos gêneros discursivos, o que nos permite afirmar que já reconheciam o uso da linguagem escrita como parte de uma necessidade de interação estabelecida entre sujeitos históricos e sociais.

Depois da leitura de um texto selecionado para ser explorado com os alunos, é normal surgirem indagações por parte do professor: é possível trabalhar esse texto com alunos no processo inicial de alfabetização/de letramento? Qual o grau de interesse dos alunos? A forma em que foi abordado o conteúdo torna-o passível de compreensão? Antes, porém, de nos determos nessas indagações, vamos retomar brevemente a fala de Geraldi, para quem "ensinar 
a língua é ampliar a experiência do aluno com a nossa" (GERALDI, 2003, p.121). Essa ideia reforça que somente com a organização e a efetivação de um trabalho mediador entre o aluno, o objeto de estudo e o professor torna-se possível a apropriação das diferentes formas de usos da linguagem.

Em se tratando de turmas no processo inicial de alfabetização, não só é possível o desenvolvimento de encaminhamentos com os gêneros discursivos, como é essencialmente necessário, pois, diante das ações e reflexões sobre a linguagem, os alunos passam a conceber o principal e real papel da oralidade e da escrita como resposta a uma necessidade no convívio social.

Por se tratar de alunos no processo inicial de aquisição da linguagem escrita, faz-se necessário a orientação do professor na reflexão sobre as características e conteúdos próprios da escrita, como disposição gráfica da escrita no papel, recursos gráficos utilizados (acentuação, segmentação e pontuação) como elementos estruturantes do discurso e suas relações com os efeitos de sentidos, de acordo com a finalidade a que se propõe. Essa apropriação acontece gradativamente, de acordo com as atividades de leitura e de escrita e as mediações propiciadas pelo conhecimento possibilitado pelo professor aos sujeitos envolvidos no processo de ensino e aprendizagem. Há também a necessidade de explorar as relações entre o registro escrito e o sistema alfabético e fonético, evidenciando a individualidade que cada letra assume no registro escrito e a construção de significados.

Ao iniciar as reflexões sobre o texto (figura 1), em específico, conversamos sobre seu contexto de produção e de circulação, enfatizando aspectos como: quem o produziu, onde, para quem, com que propósito, para circular em que meio. Refletir sobre esses elementos que, de certa forma, organizam a linguagem escrita, significa reconhecer que a língua se configura em função de uma necessidade de interação, conforme postula Bakhtin (2003). As reflexões permitiram aprofundar, um pouco mais, o conhecimento dos alunos sobre o gênero convite, atentando para sua funcionalidade na sociedade, seu conteúdo temático, sua construção composicional e seu estilo que se imbricam na organização do texto, fato que pode ser conferido nos encaminhamentos de análise.

Para proceder à atividade de análise e reflexão sobre a língua, por exemplo, abordamos inicialmente o seguinte recorte do texto: "como seu pequeno tem se desenvolvido?". A partir da leitura e reflexão desse fragmento, questionamos às crianças sobre o significado assumido pelo termo "pequeno", relacionando-o com outras situações de uso e com outras significações. Com essa relação, podemos conferir ao aluno a dinamicidade da língua e como os sentidos são construídos, tendo em vista o seu contexto de uso e a situação de interação. Logo, o emprego desse termo não se configura apenas como uma marca de estilo, mas também relaciona-se com o conteúdo temático, já que colabora com a construção de sentidos do texto naquela situação de uso da língua. Segundo Cagliari, "essa procura das relações entre significado e significante é, em outras palavras, saber como uma língua funciona e quais os usos que tem" (CAGLIARI, 2009, p. 26), e isso só se torna possível em uma atividade contextualizada, a partir do momento que substituirmos a fragmentação do nosso objeto de ensino em sala de aula. Temos que direcionar nossas ações para além da leitura de palavras, a fim de explorar o seu significado dentro de diferentes situações concretas de enunciação.

Outro aspecto interessante que exploramos com os alunos foi a própria construção do texto escrito que, relacionado com seu contexto de produção e de circulação, dão forma ao conteúdo temático: ao elaborar parte do convite com indagações, estaria a professora questionando os pais sobre o comportamento de seu filho na escola? Ela realmente esperava ouvir deles a resposta a essas perguntas? Quem poderia responder a esses questionamentos? Qual foi o propósito da professora ao fazer o convite em forma de indagações? Além disso, 
analisamos com os alunos o questionamento: "Como vai sua adaptação em nossa escola?". Pensamos juntos: para quem seria essa pergunta? Por que ela foi elaborada? Quem estaria se adaptando à escola? Entendemos que o professor, em seu privilegiado papel de mediador, deve instigar o aluno a ler e a compreender aquilo que esta lendo, indo além de uma simples decodificação do que está escrito.

Ao analisar o formato do gênero convite, verificamos, com os alunos, se o texto era capaz de cumprir com sua função social, que se resumia em convidar os pais/responsáveis a participarem da reunião promovida pela professora de seu filho, dando indicativos de onde e quando seria.

Após as atividades relacionadas à leitura e à análise linguística, e considerando as palavras de Geraldi (2003), o qual afirma que no trabalho em sala de aula deve ser considerado "[...] a produção de textos (orais ou escritos) como ponto de partida (e ponto de chegada) de todo processo de ensino/aprendizagem da língua" (GERALDI, 2003, p.135), conduzimos os alunos a várias outras atividades, envolvendo a sistematização da escrita para, posteriormente, encaminharmos para a atividade de produção escrita de texto. Para isso, apresentamos a seguinte proposta de produção:

Elaborem um CONVITE para um COLEGA que estuda nessa mesma escola, no mesmo período que você, convidando-o para apreciar nossa exposição de textos do gênero convites que vai ser realizada no dia 23/042012, após o intervalo, no saguão da escola.

Tomando como parâmetro esse encaminhamento para a produção escrita de textos do gênero convite, apresentamos, a seguir, duas produções que ilustram o resultado obtido pelos alunos, inicialmente, sem a nossa mediação, visto que o objetivo naquele momento era diagnosticar a compreensão individual de cada um em relação ao gênero e à proposta de produção, para posteriores intervenções:

Figura 2: Texto produzido pelo aluno $\mathrm{A}^{2}$

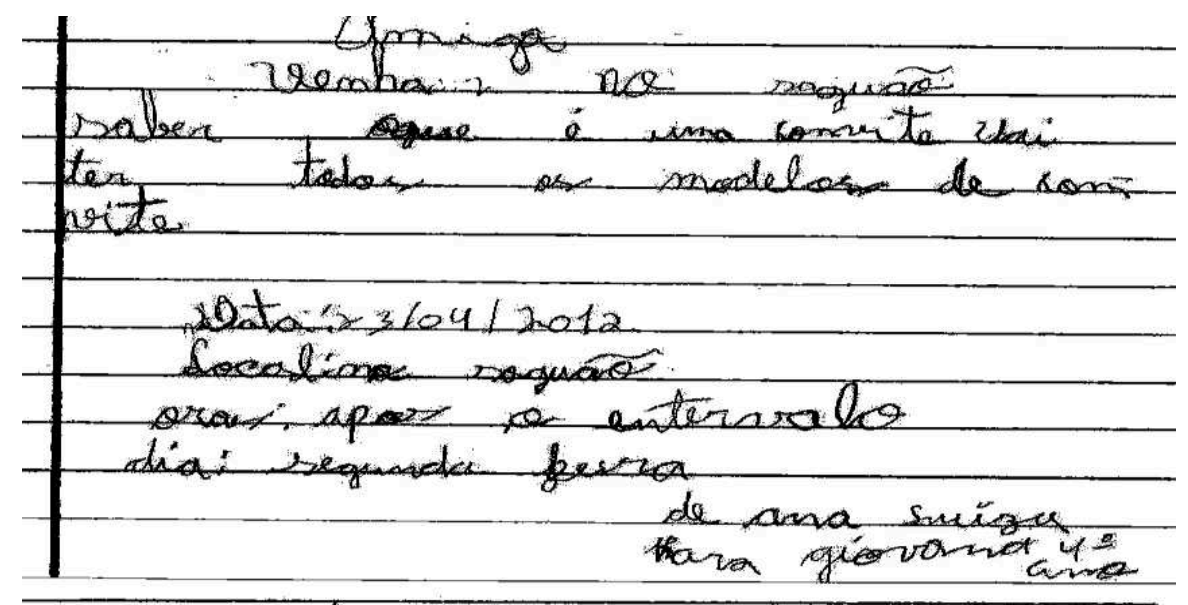

Fonte: Banco de dados da pesquisadora.

\footnotetext{
${ }^{2} \mathrm{O}$ projeto de pesquisa encontra-se amparado pelo Comitê de Ética em Pesquisa da Unioeste, sob parecer 069/2011 - CEP, uma vez que está vinculado ao Projeto do Observatório da Educação sob título: Formação Continuada para Professores da Educação Básica nos anos iniciais: ações voltadas para a Alfabetização em Municípios com Baixo IDEB da Região Oeste do Paraná. Todavia, optamos por não mencionar o nome completo dos alunos.
} 
O texto acima representa o resultado obtido pelos alunos que demonstraram uma boa compreensão não só da função social, mas também do formato do gênero. Como é possível observar, o autor coloca-se no texto como alguém que tem o que dizer e direciona-se para seu interlocutor, com quem age por meio da linguagem escrita. Cumprindo um objetivo em específico (convidar), garante as informações necessárias para que a ação com a linguagem se efetive. Sendo assim, entendemos que esse aluno, além de cumprir com seu propósito comunicativo, compreendeu a função social do gênero convite.

Para ilustrar ainda mais o resultado desse trabalho com o gênero convite na sala de aula, apresentamos mais um texto.

Figura 3: Texto produzido pelo Aluno $\mathrm{M}$

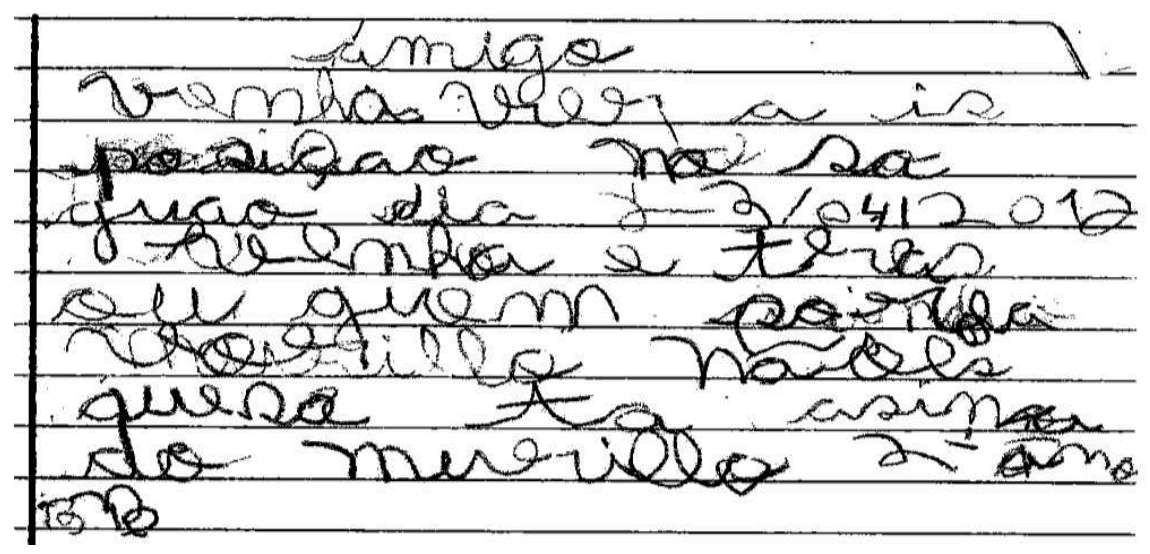

Fonte: Banco de dados da pesquisadora.

Esse texto representa os alunos que, embora tenham compreendido a função social do gênero, apresentaram maior dificuldade para sistematizá-lo, demarcando a ausência de informação, como, por exemplo, o local, além de não conseguir configurar minimamente a sua estrutura composicional. Todavia, dos 23 alunos que compõem a turma, apenas 3 se portaram dessa forma, enquanto 16 conseguiram cumprir com a proposta de produção e 4 fugiram da proposta, fazendo um convite, no entanto, para brincar ou para um aniversário. Esse resultado revelou-se de forma satisfatória para nosso trabalho, já que grande parte dos alunos respondeu com sucesso ao objetivo proposto.

Lembramos que os textos aqui expostos foram produzidos e arquivados como diagnóstico do desenvolvimento do aluno, portanto sem nenhum tipo de intervenção ainda. As intervenções foram feitas posteriormente, com atividade de análises linguística, que propiciaram a reescrita do texto, a partir da avaliação dos resultados obtidos. Para auxiliar nesse sentido, recorremos a Gonçalves (2007), para quem a organização de uma Lista de Constatações/Controle possibilita ao aluno o reconhecimento do gênero, tendo em vista sua função social e seu propósito discursivo. Esse instrumento configura-se em uma orientação por meio da qual o aluno retoma e revisa sua produção escrita, direcionando-o a superar as limitações presentes em seu texto.

Com essa finalidade, organizamos uma lista para orientar o aluno nesse processo de retomada da sua escrita, na qual procuramos contemplar questões pontuais, envolvendo a situação social de produção. Para isso, propusemos que avaliassem as informações contidas em seus textos, verificando se contemplavam os aspectos essenciais de forma que o convite cumprisse 
com sua função social. Desse modo o aluno, conforme a leitura e retomada do texto, assinalavam as opções "sim" ou "não", afirmando ou negando a presença de determinada informação pertinente ao gênero. O quadro a seguir orientou essa atividade:

Quadro 1: Avaliação do gênero convite

\begin{tabular}{|l|l|l|}
\hline \multicolumn{1}{|c|}{ Elementos que organizam o convite } & Sim & Não \\
\hline Para quem o convite se dirige? & & \\
\hline Está claro o motivo do convite? & & \\
\hline Procurou convencer? & & \\
\hline Tem a data? & & \\
\hline Tem o horário? & & \\
\hline Quem está sendo convidado? & & \\
\hline Onde vai ser a reunião? & & \\
\hline Quem está convidando? Fonte: Elaborado pela pesquisadora. & \\
\hline \multicolumn{2}{|c|}{}
\end{tabular}

Conforme podemos conferir, essa lista direciona, de certa forma, o olhar do aluno para seu próprio texto, incentivando-o a conferir e, posteriormente, reorganizar (se necessário) as informações que necessariamente devem se fazer presentes naquela produção escrita. E, a partir das constatações efetivadas, o procedimento seguinte consiste na reescrita do texto, incorporando e/ou mantendo as informações, na perspectiva de contemplar, da maneira mais eficiente possível, o propósito comunicativo.

Embora não estejamos aprofundando nossas reflexões sobre o gênero em foco, a presente análise ilustra uma das possibilidades de práticas de encaminhamentos voltadas ao trabalho com os gêneros discursivos no processo inicial de alfabetização. Durante esse período de alfabetização se faz necessário destacar a importância do papel do professor na mediação entre aquilo que o aluno faz sozinho e o que necessita de auxílio para fazer. As produções escritas irão sempre representar as apropriações já efetivadas e o distanciamento entre o conhecimento que pretendemos atingir. Nesse sentido, os resultados obtidos nos darão o direcionamento para a continuidade do trabalho. A análise em foco demonstrou, porém, que a maioria se apropriou das condições sociais do gênero convite, compreendendo sua função social e sua composição, mesmo que tenham apresentado pequenos desvios no formato, os quais poderão ser trabalhados gradativamente, conforme a situação de interação exigir desse gênero.

\section{CONSIDERAÇÕES FINAIS}

Ao abordar questões relacionadas ao ensino, Cagliari (1998) argumenta que "o que se propõe é que a escola ensine os alunos a estudar, a trabalhar com os conhecimentos, e não com o objetivo menor de ganhar nota para passar de ano" (CAGLIARI, 1998, p.10). Partilhando desse pressuposto, procuramos abordar no texto o quanto é possível e essencial à transformação do espaço da sala de aula em lugar privilegiado para a reflexão sobre a língua em sua essência, sem deixar de lado sua convencionalidade.

Para interagirmos socialmente por meio da escrita, além de compreender os diferentes discursos e suas variadas formas de organização efetivadas nos gêneros discursivos, precisamos nos apropriar de seu sistema convencional e de suas regras, e isso é um fato histórico, pois, conforme Cagliari (1998), são “[...] as regras que permitem ao leitor decifrar 
o que esta escrito e saber como o sistema de escrita funciona para usá-lo apropriadamente" (CAGLIARI,1998, p.15).

Enfim, a aprendizagem está relacionada diretamente ao ensino, portanto, para aprender é necessário que se ensine. $\mathrm{O}$ aluno por si só não é capaz de apropriar dos diferentes discursos e do sistema da escrita. É necessário que a escola ensine a ler, a escrever e, para isso, é preciso reportar também aos aspectos estruturantes da língua, aos seus mecanismos e seu funcionamento. Apresentar o alfabeto ao aluno, relacionando-o com o uso na vida social é fundamental porque sem conhecer o alfabeto, com certeza o aluno não aprenderá a ler e a escrever, assim como também apenas conhecer o alfabeto e não desenvolver uma linguagem compreensiva e interativa não garantirá a aprendizagem da escrita como meio de interação entre sujeitos históricos, sociais e concretos. O processo investigativo possibilitou-nos avaliar e refletir sobre as nossas ações no trabalho com os gêneros discursivos e a sua contribuição na apropriação da linguagem escrita pelos alunos.

Com essas considerações, tentamos demonstrar, por meio desse artigo, que é possível alfabetizar, tomando os gêneros como ponto de partida para o processo de ensino e aprendizagem e o texto escrito do aluno como revelador dos aspectos (não) dominados da escrita. A partir dessa constatação, cabe ao professor atuar como veículo de mediação da cultura da escrita, conduzindo as práticas de leituras, de análise e de produção escrita, de forma que a criança se aproprie, cada vez mais, dos usos sociais da língua.

\section{REFERÊNCIAS}

BAKHTIN, M./VOLOCHÍNOV. Marxismo e filosofia da linguagem: Problemas fundamentais do método sociológico na ciência da linguagem. Trad. Michelahud, Yara Frateschi Vieira et al. São Paulo: HUCITEC, 2004.

Os gêneros do discurso. In: Estética da criação verbal. Tradução de Paulo Bezerra. 4.ed. São Paulo: Martins Fontes, 2003. p. 261-270.

CAGLIARI, L. C. Alfabetização e Linguística. 10.ed. São Paulo: Scipione, 2009.

Alfabetizando sem o ba, be, bi, bo, bu. São Paulo: Scipione, 1998.

GERALDI, J. W. Concepções de linguagem e ensino de português. In.: O texto na sala de aula. 4. ed. São Paulo. Ática, 2006.p.39-46.

Portos de passagem. São Paulo: Martins Fonte, 2003.

GONÇALVES. Adair. Gêneros textuais e reescrita: uma proposta de intervenção interativa. Faculdade de Ciências e Letras - UNESP: Araraquara, São Paulo, 2007. (Tese de Doutorado).

MARTINS, L. M. A formação social da personalidade do professor: um enfoque vigotskiano. Campinas: Autores Associados, 2007.

MARTINS, L.; ARCE, A. O. Quem tem medo de ensinar na Educação Infantil? Em defesa do ato de ensinar. Campinas, SP. Alínea, 2007.

STEMMER, M. R. G. S. A educação Infantil e a alfabetização. In: MARTINS, L.; ARCE, A. O. Quem tem medo de ensinar na Educação Infantil? Em defesa do ato de ensinar. Campinas, SP. Alínea, 2007. p.125-146.

VYGOTSKI, L. S. A formação social da mente. 7. ed. São Paulo. Martins Fontes, 2007.

Estudos sobre a história do comportamento: o macaco, o primitivo e a criança. Tradução de Lourenço de Oliveira. Porto Alegre: Artes Médicas,1996. 
http://dx.doi.org/10.5007/1984-8420.2014v15n1p1

Obras Escolhidas. Tomo II. Madri, Espanha: A. Machado Libros, 2001.

Obras Escolhidas. Tomo III. Madri: Visor, 1995.

Recebido em: 03/06/2013

Aceito em: 07/04/2014 